\title{
Em busca de novas narrativas organizacionais: análise de conteúdo audiovisual e proposta de matriz estruturante em storytelling ${ }^{1}$
}

In the search for new organizational narratives: analysis of audiovisual content and a proposal of a structuring matrix in storytelling

En busca de nuevas narrativas organizacionales: análisis de contenido audiovisual y propuesta de matriz estructurante en storytelling

\section{Rodrigo Silveira Cogo}

- Mestre em Ciências da Comunicação pela Escola de Comunicações e Artes da Universidade de São Paulo (ECA-USP)

- Especialista em Gestão Estratégica da Comunicação Organizacional pela ECA-USP

- Graduado em Relações Públicas pela Universidade Federal de Santa Maria (UFSM)

- Consultor de pesquisa qualitativa da Ideafix Estudos Institucionais

- Gerente de Conteúdo da Associação Brasileira de Comunicação Empresarial (Aberje), onde também é professor do MBA Gestão da Comunicação Empresarial

- E-mail: rodrigocogo@usp.br

${ }^{3}$ Este artigo é parte de dissertação de mestrado defendida e aprovada no Programa de Pós-Graduação em Ciências da Comunicação da Escola de Comunicações e Artes da Universidade de São Paulo, sob orientação do professor doutor Paulo Nassar. A dissertação está integralmente disponível no Banco Digital de Teses e Dissertações da Universidade de São Paulo, no link http://www.teses.usp.br/teses/disponiveis/27/27154/tde-05122012-171130/. 


\section{Resumo}

Constatações cotidianas no fazer comunicação apontam uma distância considerável entre a projeção da identidade e a percepção gerada, o que evidencia que informar e comunicar são instâncias muito diferentes no processo de relacionamento e de diálogo. Isto é ainda mais radical numa época de multiprotagonismo, adensamento das fontes de confiança e sobrecarga de mensagens circulantes. É neste panorama que o presente estudo foi motivado e proposto: reunir, observar, analisar, entender, esquematizar e auxiliar a aplicar o formato narrativo do storytelling, especialmente aquele baseado na experiência da fonte evocadora. Trata-se de suscitar a rememoração de histórias de vida e seu entrelace com a trajetória no tempo de agentes organizacionais. É feita uma análise de conteúdo audiovisual institucional de dez organizações, pela técnica da análise estrutural da narrativa, e proposta uma matriz estruturante de elementos em storytelling.

\section{PALAVRAS-CHAVE: COMUNICAÇÃO ORGANIZACIONAL・RESPONSABILIDADE HISTÓRICA • MEMÓRIA ORGANIZACIONAL・STORYTELLING}

\section{Abstract}

Day-to-day determinations when communicating show a considerable distance between the projection of the identity and the perception generated, which makes it evident that to inform and to communicate are very different instances in the relationship and dialogue process. This is even more radical at a time of multi-protagonism, densification of the sources of trust and an overload of circulating messages. It is in this environment that this study was motivated and proposed: to bring together, analyze, understand, schematize and assist in applying the narrative format of storytelling, particularly the one based on the experience of the evoking source. It concerns the arousal of reminiscence of life histories and their interlacing with the trajectory at a time of organizational agents. An analysis is conducted of the institutional audiovisual content of ten organizations, through a technique of structural analysis of the narrative, with proposal of a structuring matrix of storytelling elements.

\section{KEYWORDS: ORGNIZATIONAL COMMUNICATION • HISTORICAL RESPONSIBILITY • ORGANIZA- TIONAL MEMORY • STORYTELLING}

\section{Resumen}

Constataciones cotidianas en el quehacer da comunicación apuntan una distancia considerable entre la proyección de la identidad y la percepción generada, lo que demuestra que informar y comunicar son instancias muy diferentes en el proceso de relacionamiento y de diálogo. Esto es todavía más radical en una época de multiprotagonismo, engrosamiento de las fuentes de confianza y sobrecarga de mensajes circulantes. Es en este panorama que el presente estudio fue motivado y propuesto: reunir, observar, analizar, entender, esquematizar y auxiliar a aplicar el formato narrativo del storytelling, especialmente aquel basado en la experiencia de la fuente evocadora. Se trata de suscitar la rememoración de historias de vida y su entrelazamiento con la trayectoria en el tiempo de agentes organizacionales. Realizado un análisis de contenido audiovisual institucional diez organizaciones, a través de la técnica del análisis estructural de la narrativa, se propone una matriz estructurante de elementos en storytelling.

PALAVRAS CLAVES: COMUNICACIÓN ORGANIZACIONAL • RESPONSABILIDAD HISTÓRICA • MEMORIA ORGANIZACIONAL・STORYTELLING 
Wá uma lacuna entre as intenções dos profissionais e de suas organizações e a efetiva atração e retenção de conteúdos e transformação de públicos de interesse. Mesmo com a crescente parafernália tecnológica dos últimos tempos, existe uma distância considerável entre a projeção da identidade e a percepção gerada. Este embate faz aflorar um dilema até bem conhecido na área: informar e comunicar são instâncias diferentes no processo de relacionamento e de diálogo, o que é ainda mais radical numa época de multiprotagonismo, adensamento das fontes de confiança e sobrecarga de mensagens circulantes. É nesse panorama que o presente artigo foi motivado e proposto: como busca por inspiração e por uma nova lógica de pensamento na estruturação de conteúdos de e sobre organizações.

Nossa proposta é reunir, observar, analisar, entender, esquematizar e auxiliar a aplicar o formato narrativo do storytelling, especialmente aquele baseado na experiência da fonte evocadora. Tratase de uma lógica de estruturação de pensamento e de um formato de organização e difusão de narrativas, por suportes impresso, audiovisual ou presencial, com base nas experiências de vida próprias ou absorvidas de um interagente, derivando daí relatos envolventes e memoráveis. O que se busca é suscitar a rememoração de histórias de vida e seu entrelace com a trajetória no tempo de agentes organizacionais, gerando conteúdos mais envolventes, significativos e memoráveis.

Pretende-se organizar e oferecer uma estrutura de análise dessas novas narrativas, com um olhar de escrutínio sobre conteúdos audiovisuais institucionais de acesso público, por meio da análise de conteúdo, pela técnica da análise estrutural da narrativa de conteúdos audiovisuais institucionais de dez organizações. O processo é encerrado com a oferta de uma matriz estruturante de elementos sobre storytelling para equalizar a configuração de conteúdos nesse paradigma com uma lente de observação única, precisa e sistematizada e com indicação de uso.

\section{ANÁLISE DE CONTEÚDO AUDIOVISUAL INSTITUCIONAL E EMBASAMENTO METODOLÓGICO}

Narrativas são especialmente relevantes para a análise dos processos organizacionais, porque as pessoas não simplesmente contam histórias, mas as sancionam, as avalizam, as institucionalizam quando as compartilham. Por meio da constatação pontual de elementos na observação da imagem em movimento, busca-se colaborar com o adensamento da produção de saber sobre o tema do storytelling diante da diversidade de abordagens correntes e neste sentido encontrar algum mérito.

Wilson C. Fonseca Júnior (2008, p. 280) diz que a análise de conteúdo "se refere a um método das ciências humanas e sociais destinado à investigação de fenômenos simbólicos por meio de várias técnicas de pesquisa". Basicamente, recorre-se ao formato como prova de cientificidade para uma descrição mais objetiva e sistemática do conteúdo manifesto de uma peça 
comunicativa. Adota-se aqui o conceito proposto por Klaus Krippendorf (1990, p. 29)², para quem "análise de conteúdo é uma técnica de investigação destinada a formular, a partir de certos dados, inferências reproduzíveis e válidas que podem se aplicar a um contexto".

Alguns estudos qualitativos seminais nesse sentido seguiram caminhos longe das escolhas tradicionais da ciência e se dirigiram ao uso de câmeras na vida cotidiana nos anos 1960, também pelo surgimento na época de dispositivos portáteis ou mesmo pela difusão crescente nas propagandas comerciais, que começaram a se infiltrar na vida das pessoas (Schnettler; Raab, 2008, p. 33). Esses pesquisadores se referem à introdução gradual e à difusão social das tecnologias de vídeo no início da década de 1980 como uma expansão comprovada de objetos de pesquisa e um incremento substancial de facilidades para análise. E o universo de possibilidades só cresceu desde então, com diversas circunstâncias de interfaces comunicativas apreendidas pela videografia, como videoconferências, videomensagens, comunicação móvel por vídeo, sistemas de vigilância por vídeo em centros de controle, interações médicas transmitidas por vídeo, teleaulas, interações em escolas, museus e outros espaços públicos, pesquisas de mercado e estudos variados de inovação e tecnologia.

Como parte das constatações de crescimento e mediatização na contemporaneidade, meios tecnológicos como fotografia, cinema, televisão, vídeo e computação vêm-se tornando umas das principais formas de comunicação do conhecimento, especialmente para compreender e interpretar realidades históricas, sociais e culturais. Aliás, a mídia audiovisual é algo que "não apenas molda, mas inerentemente determina a experiência e a memória, o conhecimento, a ação e a imaginação de compreensão social e histórica"3 (Schnettler; Raab, 2008, p. 39-40). Os vídeos oferecem uma oportunidade de capturar as ações e submetê-las a um escrutínio repetido, revendo o conteúdo e centrando a atenção em diferentes pontos a cada oportunidade.

Dentro da visão de Biber (apud Bauer, Aarts, 2008, p. 53), depois de uma análise estritamente teórica, busca-se o delineamento do corpus, com a compilação do espectro de conteúdo. Roland Barthes (2006, p. 96) define corpus como "uma coleção finita de materiais, determinada de antemão pelo analista, com arbitrariedade, e com a qual ele irá trabalhar", valendo para escolhas de conteúdo em texto, imagem, música e outros materiais como significantes da vida social - preferencialmente não misturados. Os conteúdos devem, então, ser coletados a partir da estrutura organizada na tabela 1.

\footnotetext{
2 Tradução nossa.

${ }^{3}$ Tradução nossa.
} 
Tabela 1 - Descrição da definição do corpus

\begin{tabular}{|l|l|}
\hline \multicolumn{2}{|c|}{ Descrição da definição de corpus } \\
\hline Único ponto de vista & $\begin{array}{l}\text { Conteúdo veiculado em canais ultraespeciali- } \\
\text { zados de difusão digital }\end{array}$ \\
\hline Único foco temático & $\begin{array}{l}\text { Peças comunicativas nomeadas explicitamen- } \\
\text { te como storytelling }\end{array}$ \\
\hline Única substância material & Suporte audiovisual digitalizado \\
\hline Único ciclo natural & 03 de janeiro a 31 de maio de 2012 \\
\hline
\end{tabular}

Fonte: Elaborada pelo autor.

\section{Coleta e enquadramento de dados e inferências}

Para obtenção do conjunto de materiais para análise, acionou-se um mecanismo de rastreamento digital de termos, presentes em materiais publicados em plataforma web - especificamente o serviço gratuito Google Alerts ${ }^{4}$. Além disso, foi feita uma busca por conteúdos produzidos por agências e produtoras brasileiras ${ }^{5}$ especializadas em storytelling (desde que disponibilizados em canal de vídeos), ao mesmo tempo em que se fez um acompanhamento contínuo em grupos sediados na rede social Facebook ${ }^{6}$. O perfil @storytellin ${ }^{7}$, no microblogging Twitter, difusor de conteúdos nos idiomas inglês, português, francês, espanhol e italiano, finalizou os pontos de busca. A codificação das fontes está expressa na tabela 2.

\section{Tabela 2 - Codificação de fonte do material audiovisual}

\begin{tabular}{|l|l|}
\hline \multicolumn{2}{|c|}{ Codificação de fonte do material audiovisual } \\
\hline 01 & Termos monitorados via Google Alerts \\
\hline 02 & Perfil Twitter \\
\hline 03 & Grupos do Facebook \\
\hline 04 & Site fornecedores \\
\hline
\end{tabular}

Fonte: Elaborada pelo autor.

\footnotetext{
${ }^{4} \mathrm{O}$ Google Alerts é um serviço online gratuito, fornecido pela empresa Google Inc, que faz uma varredura de termos de pesquisa escolhidos em todas as publicações em páginas da web, artigos de jornal digital e blogs e sempre, ao encontrar novos resultados, os envia por e-mail ao solicitante. É preciso ter cadastro formal junto aos produtos Google, que neste caso foi realizado com o endereço rodrigoscogo@gmail.com, ativado especialmente para a tarefa. Veja mais sobre a política de uso em https://support.google.com/alerts/bin/answer.py?hl=pt=-BR\&answer175925=\&topic28415=\&parent$28413 \&$ rd=1.

${ }^{5} \mathrm{O}$ monitoramento de conteúdo publicado aconteceu nos websites das empresas brasileiras The Alchemists (http://www. thealchemists.com/blog) e Lukso Story \& Strategy (http://www.lukso.com.br/site).

6 Para mais informações sobre os grupos, consultar suas páginas de interação: Storytelling Transmedia (http://www.facebook.com/groups/198082870240829) e Era Transmídia (http://www.facebook.com/groups/transmidia).

${ }^{7}$ Para visualizar o tipo de informação veiculada pelo perfil no Twitter, basta visitar https://twitter.com/\#!/storytelling.
} 
Foram listados no período trinta vídeos. A este contingente foi aplicado um sorteio aleatório com saltos simétricos de três conteúdos. Ou seja, para cada trio de vídeos cronologicamente agrupados, o primeiro e o terceiro foram excluídos, resultando em dez materiais audiovisuais ${ }^{8}$. A tabela 3 organiza esse conjunto de peças por empresa, tipo e duração, bem como sinaliza sua codificação.

O conjunto de peças comunicativas foi selecionado, registrado e transcrito segundo dimensões visual e verbal, e depois foi feita uma análise de elementos constitutivos da história, na forma de voz narrativa, sequência no tempo, ambientação, personagens e estrutura valorativa.

Tabela 3 - Codificação de material audiovisual indicado como storytelling

\begin{tabular}{|c|l|l|l|}
\hline Código & \multicolumn{1}{|c|}{ Empresa } & \multicolumn{1}{|c|}{ Tipo } & Duração \\
\hline 01 & Caixa & Vídeopublicitário institucional de memória & $1 \mathrm{~min}$ \\
\hline 02 & Allianz & Vídeo de projeto institucional & $1 \mathrm{~min} 25 \mathrm{~s}$ \\
\hline 03 & Roche & Vídeo de projeto de responsabilidade social & $1 \mathrm{~min} 29 \mathrm{~s}$ \\
\hline 04 & Laboratório Fleury & Vídeo publicitário institucional & $30 \mathrm{~s}$ \\
\hline 05 & Campari Brasil & Vídeo de projeto de memória empresarial & $3 \mathrm{~min} 3 \mathrm{~s}$ \\
\hline 06 & Metrô São Paulo & Vídeo publicitário institucional & $45 \mathrm{~s}$ \\
\hline 07 & TAM & Vídeo de projeto de memória empresarial & $1 \mathrm{~min}$ \\
\hline 08 & Vale & Vídeo de projeto de segurança no trabalho & $4 \mathrm{~min} 5 \mathrm{~s}$ \\
\hline 09 & Coca-Cola & Vídeo de projeto de responsabilidade social & $2 \mathrm{~min} 42 \mathrm{~s}$ \\
\hline 10 & Fiat & Vídeo de projeto de memória empresarial & $2 \mathrm{~min} 38 \mathrm{~s}$ \\
\hline
\end{tabular}

Fonte: Elaborada pelo autor.

A seguir, constam, a título de duas análises de conteúdos individualizadas.

\section{Vídeo da Allianz}

Por meio de post em grupo especializado no Facebook, veio a indicação de projeto institucional "Deixe seu conselho. Compartilhe sua experiência", implementado pela empresa de seguros Allianz. Trata-se da coleta de dicas de cidadãos, mediante um website específico, com vistas a aumentar a segurança e o bem-estar das pessoas. Não há vínculo obrigatório entre depoente e a empresa, tampouco necessidade de qualquer menção sobre o tipo de serviço prestado na área seguradora. Os aconselhamentos são enviados por texto, em formulário próprio, e depois gravados pela equipe do projeto para disponibilização na internet. O caso divulgado no grupo da rede social mencionada é do narrador Wagner.

A voz narrativa desse vídeo de projeto institucional tem evocação de fala vinda diretamente do

\footnotetext{
${ }^{8}$ Todos os materiais audiovisuais digitalizados que foram sorteados para a análise detalhada estão disponíveis para visualização completa no link agrupado http://www.youtube.com/watch?v=|TV_biOni-k
} 
protagonista da história. O relato do vivido acontece sem intermediários, com pequenas intervenções somente no início e no final da gravação pelo produtor ou diretor da peça comunicativa, em fala quase inaudível. O repertório é cotidiano, com conjugações verbais fora de normas gramaticais e com contrações de palavras como "cê" para indicar "você", dando tom coloquial, próximo da conversa do dia a dia, num estilo confessional. O gaguejo ou troca de palavras durante o relato, sem haver nenhuma edição posterior, remete à intenção de veracidade do depoimento. O narrador é um cidadão comum, sem representação institucional qualquer da marca da seguradora. A sequência no tempo é de narrativa de tempo passado - ano 2005 identificado no depoimento, com lembrança de fato ocorrido com o narrador. É oferecido como "conselho", dentro da proposta do projeto da seguradora, o reconhecimento da possibilidade de acontecerem imprevistos e da importância de ter alguém disponível para ir atrás das pessoas envolvidas num determinado incidente. No caso, o narrador Wagner e um grupo de amigos foi envolvido num acidente de automóvel e ele, por questões explicadas no vídeo, entende haver morrido. A história tem início, meio e fim, ainda que com lacunas para agilizar o relato e deixar um sentido aberto para a imaginação do espectador.

Quanto à ambientação, não existe nenhum outro elemento visual de vigor, além do narrador em close-up. Um muro coberto por vegetação aparece ao fundo, com imagem desfocada. $O$ ângulo lateral da gravação busca dar intimismo, como se o espectador estivesse escutando e partilhando a história como voyeur. Como personagens, há o Wagner como principal - narrador e protagonista da história contada -, com aparição sem relevância dos demais amigos envolvidos no incidente, mas sem nominação ou caracterização. Como segunda voz, há o diretor da peça comunicativa como um registro do caráter ao vivo e sem cortes do depoimento. Não há assinatura institucional.

Sobre a estrutura valorativa, é interessante registrar que a história relatada de ocorrência de trânsito e mesmo a faixa etária jovem e o estilo despojado do narrador são marcas retóricas para concluir sobre a importância de contratar um seguro - uma segurança, já que nunca se sabe quando algo pode ocorrer. A simplicidade do relato cumpre o papel de aproximar o espectador da história, sem vocabulário erudito ou formal, conotando uma pureza ou genuinidade no depoente como alguém que fala a verdade e não incorre em artificialismos que afastam o espectador ou colocam em dúvida a sinceridade da história.

\section{Vídeo da Vale}

Num projeto voltado para a segurança e o bem-estar de seus empregados, a mineradora Vale promoveu em julho de 2011 o "dia de reflexão". Durante uma hora, todos os que trabalham nas unidades da empresa foram convocados a parar suas atividades para refletir sobre a importância da segurança para a vida. Um vídeo foi produzido especialmente para a ocasião, no qual 
pessoas falavam de seu amor por outras pessoas, da ocorrência de algum incidente que levava à morte e da saudade que tinham delas por consequência. Todos os depoentes não eram funcionários da Vale. A intenção era despertar para o uso de equipamentos individuais de proteção no expediente de trabalho. Esse material chegou ao conhecimento desta pesquisa pelo monitoramento do Google Alerts.

A voz narrativa é de relato do vivido diretamente feito pelos narradores das experiências. Os letreiros de condução do conjunto de histórias de luto com perguntas e mais a logomarca final representam a voz institucional do conteúdo audiovisual, mas em tom absolutamente sutil. A sequência é de narrativa de tempo presente em todos os depoimentos, rememorando mortes entre familiares ocorridas no passado. Os sentimentos são atualizados à luz do luto, da ausência, da saudade. As perguntas condutoras da narrativa institucional são no tempo presente com intenção de mudança de atitude futura. Não existem marcadores de tempo cronológico - todas as histórias trazem sensação de recência imediata, dado o tema.

Em termos de ambientação, o foco é extremo nos depoimentos de vida, com força emotiva, em suas especificidades de som, de olhar, de gestos, de expressões labiais. A presença de tomadas de câmera transitando entre planos próximos distintos busca gerar intimidade do espectador. $\mathrm{O}$ cenário inexistente durante os relatos, de fundo preto com pequena luminosidade, também serve ao propósito intimista. Breves elementos em imagem estática de folha no chão, parte de lápide, inscrição "sauda..." foram empregados para gerar lembrança de cemitério, na transição do tema durante o argumento. Quanto a personagens, são 21 narradores, intercalados em partes semelhantes das suas evocações e em planos de filmagem distintos. Há uma evidente diversidade de tipos humanos, até para mostrar que a morte e o luto são inadiáveis para todos os tipos de pessoas, independentemente de raças, gêneros, faixas etárias, traços culturais no vestir, idiomas. A assinatura com logomarca funciona como $22^{\circ}$ personagem, desvendado ao final do conteúdo audiovisual como autor dos letreiros-pergunta que conduzem o raciocínio e dividem as partes dos depoimentos transmitidos. Todas as pessoas já falecidas lembradas pelas histórias também são personagens, embora sem caracterização, nome ou aparição por foto - com uma única exceção, cuja imagem é mostrada em carteira de identidade.

Na estrutura valorativa, é importante ressaltar que o argumento da saúde e segurança, que teria tendências racionais de uso de equipamentos de proteção, atendimento da legislação vigente e outros indicadores quantitativos e lógicos, cede espaço para a narrativa da sensibilidade. A intenção retórica é inspirada no que acontece na ausência de saúde e segurança e nos efeitos para os familiares das pessoas. Trata-se de uma proposta inteligente da mineradora em projetar o futuro da falta e da saudade para estruturar um presente de maior responsabilidade no exercício do trabalho. O forte apelo emotivo cativa a atenção, mesmo pela experiência de desconhecidos, já que se trata de uma sensação universal. Há sobreidentificação com os variados tipos de história de perda, chegando a diferentes tipos de espectadores na mobilização de tempo. 
A conclusão moral é que aquele que não utiliza equipamentos de proteção no trabalho e é leviano com a própria vida tende a ser mal visto ou mal interpretado pelos demais, porque seu egoísmo causa dor naqueles que lhe querem bem, evidenciando a interdependência das pessoas e do mundo como um todo.

\section{PROPOSTA DA MATRIZ ESTRUTURANTE DE STORYTELLING}

A partir dos vídeos analisados, buscou-se a formatação de uma matriz de elementos estruturantes de storytelling. Sugere-se a existência de determinadas características praticamente imprescindíveis de serem consideradas pelos comunicadores na hora de planejar, criar e produzir conteúdos audiovisuais institucionais nesse tipo de formato. Organizou-se um diagrama com dados cruzados, como se vê na tabela 4. Nela, constam na horizontal os códigos dos dez vídeos analisados e na vertical uma série de dez pontos de caracterização típicos do storytelling, a saber: tom confessional; narrativa em primeira pessoa; relato lacunar; fala lateralizada; repertório coloquial; exposição de vulnerabilidade; proposta inspiracional; universalidade temática; jogo de suspense e curiosidade; e vigor emocional.

Tom confessional diz respeito a uma inflexão de voz em ritmo e timbre que pareçam simular ou de fato expor a evocação de um segredo ou de uma história íntima, sobre a qual se fala pela primeira vez em público e com relativa timidez ou cautela. Já narrativa em primeira pessoa é a preferência pelo uso dos pronomes pessoais eu e nós nos relatos e pelo uso de verbos conjugados e pronomes possessivos nesse enfoque. Por relato lacunar entenda-se, sim, a história ser rememorada com início, meio e fim, mas por vezes economizando em detalhamentos ou fazendo pulos temporais para que o próprio espectador preencha os espaços em sua mente, numa construção narrativa de sentido aberto (cuja interpretação final acontece a partir do imaginário de cada interagente no processo da contar a história). Na fala lateralizada, a busca é por tomadas de câmera em que o narrador esteja posicionado com o corpo ou o olhar em ângulo paralelo ao foco da gravação, instigando o espectador a ser um voyeur, como uma bisbilhotice sobre a conversa alheia. Essa opção também influencia na sensação de intimismo da narrativa, como se algo fosse ser confessado sem saber-se que outros escutam, bem como na atribuição de veracidade - não é alguém que fala diretamente para o espectador, com a intenção de convencê-lo sobre algo; o narrador apenas relata.

O repertório coloquial diz respeito a permissão e incentivo para vocabulários mais simples, sem rebuscamentos estilísticos ou técnicos, o que torna a narração mais próxima de maior número de pessoas e não se apresenta como excludente ou arrogante. Há espaço aqui inclusive para imprecisões frente à gramática estabelecida, neologismos e mesmo gaguejos, interjeições variadas, repetição de palavras ou expressões. O elemento exposição de vulnerabilidade faz parte da matriz para garantir o direito de uso de histórias de fracasso, ou ao menos fora do escopo do 
sucesso e da vitória peculiares à cultura ocidental. Abre-se possibilidade para características de pessoas ou de desenrolar de fatos que não sejam necessariamente meritórias, corretas, bemsucedidas, sem imprevistos. As vulnerabilidades, as fragilidades ou os pontos a melhorar do narrador ou de sua trajetória podem ser marcas fortes de atribuição de transparência à história contada. Em proposta inspiracional deseja-se contemplar nas narrativas a intenção do relato de servir, com o rememorar do passado no tempo presente, como base para consolidar transformações na ação futura. A busca de influência sobre o efeito final após a evocação do depoimento é por motivação nos interagentes, por auxílio na visualização de novos caminhos para seus dilemas, pela inspiração de que outra história pode ser contada. Já com universalidade temática quer-se dizer da amplitude do tema tratado na história, em que a aparição de questões que sejam possíveis e alcançáveis por maior número de pessoas acabe por dar mais aderência ao conteúdo, por ter retido mais a atenção. É o que se vê nas histórias que envolvem animais ou bebês, que têm ligação com artes e natureza, que contemplam situações-chave de ritos e rituais como nascimento, batismo, entrada na escola, aniversário de quinze anos, formatura, vestibular, primeiro emprego, promoção, casamento e morte, entre outros. A ideia do elemento jogo de suspense e curiosidade faz parte dos relatos que prevejam dar conhecimento dos fatos e dos detalhes para os demais interagentes de forma programada, com identificação mais precisa possível de cenário, personagens, trama, evento incitante, clímax, resolução de questões num todo coerente dentro do tempo predeterminado de duração do conteúdo comunicativo. Por fim, o vigor emocional é a capacidade de a história contada despertar afetividades mais profundas nos interagentes, na forma de sentimentos - explícitos ou não - de riso, de alegria, de choro, de tristeza, de reflexão, de recusa, de aceite, com intensidade suficiente para não gerar indiferença.

Tabela 4 - Proposta de matriz estruturante de elementos de storytelling

\begin{tabular}{|l|c|c|c|c|c|c|c|c|c|c|c|}
\hline \multicolumn{1}{|c|}{ Elementos } & \multicolumn{6}{c|}{ Código dos conteúdos audiovisuais selecionados } \\
\hline & $\mathrm{V} 1$ & $\mathrm{~V} 2$ & $\mathrm{~V} 3$ & $\mathrm{~V} 4$ & $\mathrm{~V} 5$ & $\mathrm{~V} 6$ & $\mathrm{~V} 7$ & $\mathrm{~V} 8$ & $\mathrm{~V} 9$ & $\mathrm{~V} 10$ \\
\hline Tom confessional & & $\mathrm{x}$ & $\mathrm{x}$ & & $\mathrm{x}$ & $\mathrm{x}$ & $\mathrm{x}$ & $\mathrm{x}$ & $\mathrm{x}$ & $\mathrm{x}$ \\
\hline Narrativa em primeira pessoa & & $\mathrm{x}$ & $\mathrm{x}$ & & $\mathrm{x}$ & $\mathrm{x}$ & $\mathrm{x}$ & $\mathrm{x}$ & $\mathrm{x}$ & $\mathrm{x}$ \\
\hline Relato lacunar & $\mathrm{x}$ & $\mathrm{x}$ & $\mathrm{x}$ & $\mathrm{x}$ & $\mathrm{x}$ & $\mathrm{x}$ & $\mathrm{x}$ & $\mathrm{x}$ & $\mathrm{x}$ & $\mathrm{x}$ \\
\hline Fala lateralizada & & $\mathrm{x}$ & $\mathrm{x}$ & $\mathrm{x}$ & $\mathrm{x}$ & $\mathrm{x}$ & $\mathrm{x}$ & $\mathrm{x}$ & $\mathrm{x}$ & $\mathrm{x}$ \\
\hline Repertório coloquial & & $\mathrm{x}$ & $\mathrm{x}$ & $\mathrm{x}$ & $\mathrm{x}$ & $\mathrm{x}$ & $\mathrm{x}$ & $\mathrm{x}$ & $\mathrm{x}$ & $\mathrm{x}$ \\
\hline Exposição de vulnerabilidade & & $\mathrm{x}$ & $\mathrm{x}$ & $\mathrm{x}$ & & & & $\mathrm{x}$ & $\mathrm{x}$ & \\
\hline $\begin{array}{l}\text { Proposta } \\
\text { inspiracional }\end{array}$ & $\mathrm{x}$ & $\mathrm{x}$ & $\mathrm{x}$ & $\mathrm{x}$ & $\mathrm{x}$ & $\mathrm{x}$ & $\mathrm{x}$ & $\mathrm{x}$ & $\mathrm{x}$ & $\mathrm{x}$ \\
\hline Universalidade temática & & $\mathrm{x}$ & & $\mathrm{x}$ & $\mathrm{x}$ & $\mathrm{x}$ & $\mathrm{x}$ & $\mathrm{x}$ & & $\mathrm{x}$ \\
\hline
\end{tabular}




\begin{tabular}{|l|c|c|c|c|c|c|c|c|c|c|}
\hline $\begin{array}{l}\text { Jogo de suspense } \\
\text { e curiosidade }\end{array}$ & $\mathrm{x}$ & $\mathrm{x}$ & & & & $\mathrm{x}$ & & $\mathrm{x}$ & & $\mathrm{x}$ \\
\hline Vigor emocional & $\mathrm{x}$ & $\mathrm{x}$ & $\mathrm{x}$ & $\mathrm{x}$ & & $\mathrm{x}$ & $\mathrm{x}$ & $\mathrm{x}$ & $\mathrm{x}$ & $\mathrm{x}$ \\
\hline
\end{tabular}

Fonte: Elaborada pelo autor.

Dos materiais audiovisuais institucionais digitalizados, vindos de várias fontes, que serviram ao estudo de campo, constata-se que $90 \%$ contêm a maioria dos elementos sugeridos como basilares na construção no formato de storytelling pela narrativa da experiência. Isso é positivo em termos de confiança nas fontes especializadas, que estão atribuindo corretamente a terminologia a conteúdos que de fato seriam storytelling do ponto de vista da bibliografia de referência. Mas é interessante ressaltar que apenas dois conseguem completar toda a matriz de elementos - quais sejam as peças comunicativas da seguradora Allianz e da mineradora Vale, sendo que outros dois têm nove dos dez itens teoricamente indicados a figurar - os vídeos "Metrô SP - 40 anos" e "Fiat - 35 anos".

Apenas dois elementos - relato lacunar e proposta inspiracional - estão presentes em todos os vídeos analisados, o que mostra o espaço para incremento nessas narrativas em termos de lapidação e maior atratividade. Junto a isso, por outro lado, veem-se características que são quase dominantes nos conteúdos em foco, quais sejam a fala lateralizada, o repertório coloquial e o vigor emocional, presentes em $90 \%$ dos vídeos.

Em termos de menor aparição, mas ainda assim encontrados em $50 \%$ dos casos, tem-se dois elementos: o jogo de suspense e curiosidade e a exposição de vulnerabilidade. Na primeira ocorrência, a explicação parece muito clara: os relatos de vida gravados da evocação direta da experiência das pessoas não necessariamente estão estruturados em termos de uma história ordenada ou planejada - a memória vem em turbilhão e para a narrativa decorrente não se escolhem cronologias, etapas, silêncios ou juízos de valor prévios. Assim, as histórias ganham em genuinidade, mas perdem em potencialidade de longevidade do poder de atração. Ao mesmo tempo, é importante considerar que não existe nenhum vídeo analisado neste trabalho com duração superior a quatro minutos, sendo muito mais difícil nesse espaço de tempo o desenvolvimento de uma história com início, meio e fim e ainda detalhamentos e fases que permitam o jogo requisitado pela matriz. Que a exposição de vulnerabilidade esteja somente na metade dos vídeos, é porque ela constitui tema ainda bastante sensível em comunicações empresariais locus pleno de narrativas de êxito e com pouco espaço para as não-conformidades dentro das regras estabelecidas, entre outros motivos para resguardar mitologias em torno da infalibilidade das lideranças e dos fundadores dos negócios. Essa aura de perfeição com a qual se revestem os gestores é difícil de ser superada em nome de figuras mais humanizadas e reais.

Apesar de todos os conteúdos audiovisuais selecionados apresentarem voz narrativa com narrador direto, de viva-voz na tela, esse fator não é garantia de alcance do elemento narrativa em 
primeira pessoa. O motivo é simples: o depoente pode fazer uma evocação de histórias de terceiros não presentes na cena, utilizando portanto pronomes pessoais e possessivos na terceira pessoa. De toda maneira, convém assinalar que o elemento fala lateralizada é generalizado entre os conteúdos que empregam narração direta - ou seja, não há depoimento com olhar focado na câmera. Os materiais de maior índice de alcance da matriz estruturante, quais sejam V2 e V8, em relação à voz narrativa, demonstram uma diversidade interessante: o primeiro tem somente narrador direto, visível de maneira permanente na tela, e o segundo tem 21 personagens, que se alternam entre fala direta e voz em off, além da voz institucional da assinatura e de letreiros condutores do argumento.

Numa análise das formas de aparição da sequência no tempo nos conteúdos audiovisuais selecionados, evidencia-se que $90 \%$ dos vídeos que têm projeção de futuro também apresentam exposição de vulnerabilidade. Daí depreende-se que, ao mostrar algum tipo de fragilidade do narrador ou dos personagens da história vivida, imediatamente os materiais indicam um futuro de transformação, em que o problema possa ser superado. É assim nos materiais V2, V3, V8 e V9. A vulnerabilidade não se dá como peso ou fato consumado, mas como propulsora de mudança.

A respeito da ambientação, algumas constatações são importantes. A existência de entorno desfocado no vídeo, embora auxilie na construção de um clima de introspecção e sem outros fatores de distração, não é condição para que se dê um tom confessional. Os únicos materiais que não apresentam o elemento tom confessional, quais sejam o V1 e o V4, têm, no entanto, o entorno desfocado. Entre os dois materiais que têm 100\% dos elementos da matriz estruturante, vê-se novamente uma diversidade de opções: enquanto o V2 é feito com entorno desfocado e aparição de elementos da natureza, o V8 está exclusivamente em cenário artificial de estúdio. Ainda que cenário artificial seja utilizado somente em $20 \%$ dos vídeos selecionados - e inclusive naquele de menor índice de elementos da matriz (40\%) como no caso do V1, o que pode demonstrar sua pouca adequação ao formato, não é possível atribuir a essa ambientação montada uma relação negativa com um bom trabalho final baseado em storytelling.

A proposta da "matriz estruturante de elementos de storytelling" é servir como uma lente sobre a qual os conteúdos audiovisuais de organizações podem ser vistos, buscando a maior contemplação possível de características que conformam esse formato narrativo. Tendo clareza da potencialidade do storytelling e dos requisitos mínimos para configuração de sua estrutura discursiva, certamente os comunicadores poderão produzir peças mais assertivas e diferenciadas em relação ao estilo convencional de informação e relacionamento. Naturalmente que a matriz não se esgota no presente trabalho e seria necessário testá-la com outros materiais de base e também adequada para storytelling em suporte impresso.

\section{CONSIDERAÇÕES FINAIS}

Storytelling faz parte de um processo de posicionamento, de expressão e de troca entre organizações e indivíduos e grupos. Trata-se de um recurso plenamente adequado a um panorama de 
reconhecimento da multiplicidade de vozes e do descentramento do sujeito corporativo - onde as instâncias de poder são flexibilizadas, há um considerável aumento de conteúdos em circulação de diversas fontes e os ambientes de trabalho exigem relações mais humanizadas. Em cenários como este, comunicação de mando e de produtivismo tem alcance reduzido em médio e longo prazos. Mais ainda, escolhas narrativas, impregnadas deste jeito tradicional de ver o mundo, podem conter simbolismos que boicotam esforços de cunho participativo ou dialógico.

Por isto, storytelling também constitui uma prova de existência de um espaço de democracia e de capacidade de escuta para além da polifonia ou do teor encantador e comprovadamente magnetizante de suas evocações: também pode ser visto como resultado da vontade de compartilhamento, da cumplicidade frente ao futuro e da consciência sobre a importância de cada um na conquista coletiva - mesmo entre agentes cujos objetivos nem sempre são e serão alinhados, dadas as contradições inerentes às relações de trabalho na operação capitalista.

As evidências da pesquisa de campo parecem animadoras. Ainda que não se possa falar numa prevalência estrutural nas narrativas da experiência pelo suporte audiovisual, e que o mercado produtor e veiculador esteja ainda sem balizadores na construção da forma de seus argumentos por storytelling, há diversas coincidências de uso entre a proposição teórica arrolada e a prática comprovada. Os elementos na matriz de análise oferecida, após exaustiva revisão bibliográfica, estão presentes na maioria do material sorteado para escrutínio. Vindos de fornecedores distintos e de organizações de segmentos de negócio diversos, em tempos de veiculação igualmente díspares e para temáticas variadas, os vídeos trazem similaridades de composição - ainda que isto possa ser mais uma coincidência do que propriamente uma lucidez na aplicação do recurso. Claro que o caráter inédito e inesperado da essência da história contada permanecerá fora do controle, bem como a reação efetiva do espectador, porque originadas da experiência do outro, contribuinte do sentido e do significado e não audiência passiva. Isso faz parte do trabalho de desapego do comunicador que antes imaginava orquestrar o entendimento do mundo sobre produtos, marcas e organizações. Novos tempos, novas negociações, novas linguagens.

Por esses fatores, consideram-se o conhecimento, a compreensão e a absorção dessa nova lógica comunicacional como fundamentais numa era marcada pela busca de relacionamentos sustentáveis. O storytelling pode ser a voz deste novo tempo: conversacional, inclusivo, colaborativo, afetivo, duradouro e memorável.

\section{REFERÊNCIAS}

BARTHES, Roland. Introdução à análise estrutural da narrativa. In: BARTHES, Roland (Org). Análise estrutural da narrativa. 4. ed. Petrópolis (RJ): Vozes, 1976. p. 19-60.

BAUER, Martin; AARTS, Bas. A construção do corpus: um princípio para a coleta de dados qualitativos. In: BAUER, Martin;

GASKELL, George (Ed.). Pesquisa qualitativa com texto, imagem e som: um manual prático. Trad. de Pedrinho A. Guareschi. 7. ed. Petrópolis (RJ): Vozes, 2008. p. 39-63. 
FONSECA JUNIOR, Wilson Corrêa. Análise de conteúdo. In: DUARTE, Jorge; BARROS, Antonio (Org.). Métodos e técnicas de pesquisa em comunicação. 2. ed. São Paulo: Atlas, 2008. p.280-304.

KRIPPENDORF, Klaus. Metodologia de análisis de contenido. Barcelona: Paidós, 1990.

SCHNETTLER, Bernt; RAAB, Jürgen. Interpretative visual analysis: developments, state of the art and pending problems. Qualitative Social Research, v. 9, n. 3, set. 2008. Disponível em: <http://www.qualitative-research.net/index.php/fqs/article/ view/1149/2556>. Acesso em: 02 maio 2012.

Recebido em: 16.09.2012 / Aceito em: 21.03.2013 